\title{
Posisi Kerja dan Kelelahan pada Pekerja Rotan di CV. Fajar Baru Kecamatan Palu Utara
}

\author{
Herlina S. Sunuh, Saharudin, Herdi \\ Jurusan Kesehatan Lingkungan, Poltekkes Kemenkes Palu, Indonesia \\ Email: herlinassunuh@gmail.com
}

\begin{abstract}
Work position is a determining point in doing work. If the work position performed by the worker is not ergonomic, it will cause work fatigue and result in accidents. Fatigue is a process of decreasing the efficiency of work implementation and reducing the physical strength or endurance of the human body to continue activities that should be done. This reaserch aimed to determine the work position and fatigue of rattan workers at CV Fajar Baru, Kayumalue Ngapa Village, North Palu District. This research is descriptive with an observational, population and sample approach.There are 60 workers in the production division of CV Fajar Baru, Kayumalue Ngapa Village, North Palu are taken as sample. The results of the research, appropriate work position (0\%), inappropriate as many as 60 workers (100\%), normal fatigue as many as 5 workers (8.3\%), mild as many as 47 workers (76.7\%), moderate as many as 8 workers $(15,0 \%)$ and Heavy (0\%). It is recommended that the company takes care of the good working posture of their employees, for example providing the use of rest breaks after performing standing position for two hours. It must be interspersed with rest periods, the position of lifting the spine straight, not bending too much and the position when moving the load should be close to the body, the movement should be dynamic, and make complete facilities according to labor anthropometry.
\end{abstract}

Keywords: Work position, work fatigue, rattan workers

\begin{abstract}
ABSTRAK
Posisi kerja merupakan titik penentu dalam melakukan pekerjaan, jika posisi kerja yang dilakukan oleh pekerja tidak ergonomis, akan menyebabkan kelelahan kerja dan berakibat kecelakaan. Kelelahan adalah merupakan proses menurunnya efesiensi pelaksanaan kerja dan berkurangnya kekuatan atau ketahanan fisik tubuh manusia untuk melanjutkan kegiatan yang seharusnya di kerjakan. Tujuan penelitian ini untuk mengetahui posisi kerja dan kelelahan pada pekerja rotan Di CV Fajar Baru Kelurahan Kayumalue Ngapa Kecamatan Palu Utara. Jenis penelitian adalah deskriptif dengan pendekatan observasional, populasi dan sampel yaitu seluruh pekerja dibagian produksi CV Fajar Baru Kelurahan Kayumalue Ngapa Kecamatan Palu Utara sebanyak 60 orang. Hasil penelitian, posisi kerja sesuai $(0 \%)$, tidak sesuai sebanyak 60 pekerja (100\%), kelelahan Normal sebanyak 5 perkerja $(8,3 \%)$, Ringan sebanyak 47 pekerja (76.7\%), Sedang sebanyak 8 orang pekerja (15,0\%) dan Berat $(0 \%)$. Sebagai saran agar perusahaan dapat memperhatikan posisi kerja pekerja yang benar seperti lama berdiri 2 jam harus diselingi waktu istirahat, posisi mengangkat tulang belakang lurus, tidak terlalu membungkuk dan posisi saat memindahkan beban harus dekat dengan tubuh, sebaiknya gerakan harus dinamis, serta membuat kelengkapan sarana yang sesuai antropometri tenaga kerja.
\end{abstract}

Kata kunci: Posisi kerja, kelelahan kerja, pekerja rotan 


\section{PENDAHULUAN}

Kemajuan teknologi beriringan dengan pembangunan gedung serta aktifitas konstruksi yang memberikan kontribusi resiko bahaya pada tenaga kerja berupa kejadian kecelakaan kerja. Salah satu pemicu utama kecelakaan kerja yang diakibatkan oleh faktor individu adalah kelelahan kerja. ${ }^{1}$ Dalam kasus keselamatan dan kesehatan kerja salah satu yang menjadi pemicu terjadinya kecelakaan adalah kelelahan kerja. Kelelahan kerja bias diakibatkan aspek manusia maupun faktor luar manusia sepeti area tempat kerja berupa desain kerja. Kelelahan kerja wajib untuk diperhatikan, sebab kelelahan pada pekerja dapat berakibat terhadap berkurangnya kuantitas maupun kualitas kerja Salah satu factor pemicu terjadinya kelelahan kerja seperti posisi tubuh yang dan penurunan konsentrasi kerja. ${ }^{2}$

Posisi kerja yang tidak berubah-ubah dengan menggunakan tenaga $50 \%$ dari kekuatan maksimal hanya mampu bertahan selama 60 detik, tetapi bila menggunakan tenaga $<20 \%$, kerja fisik mamt bertahan lama, jika kemampuan pergerakan otot yang menetap sebesar 15 - 20 dapat mengakibatkan kelelahan dan rasa sakit apabila beban kerjanya setiap hari berlangsung lama. Astrand dan Rodahl berpendapat bahwa orang dapat melakukan pekerjaan beberapa jam per hari tanpa gejala kelelahan jika tenaga yang dikeluarkan tidak melebihi $8 \%$ dari maksimum tenaga otot. ${ }^{3}$

Setiap tahun sebanyak 2 juta pekerja menjadi korban kecelaakaan kerja yang disebabkan faktor kelelahan. Dari 58.115 sampel ada 18.828 sampel $(32,80 \%)$ di antaranya mengalami kelelahan dan sangat berpengaruh pada produktivitas kerja. ${ }^{4} \mathrm{Di}$ Indonesia data menunjukkan bahwa sebanyak 103.283 kasus kecelakaan kerja akibat kelelahan. Jumlah ini meningkat dari tahun ke tahunnya bila dibandingkan angka kecelakaan kerja pada tahun 2010 terdapat 98.711 kasus tahun 2011 terdapat 99.491 kasus tahun 2012 terdapat 103.074 kasus, serta setiap harinya ada 9 pekerja peserta Jamsostek meninggal dunia akibat kecelakaan kerja. ${ }^{5}$

Data Dinas Tenaga Kerja dan Transmigrasi (Disnaketrans) Provinsi Sulawesi Tengah pada tahun 2019 dari 1244 perusahaan yang ada tercatat 83 orang mengalami kasus kecelakaan kerja akibat kelelahan kerja. Sehingga penelitian ini bertujuan ingin mengetahui Posisi Kerja Dan Kelelahan Pada Pekerja Rotan Di CV. Fajar Baru Kelurahan Kayumalue Ngapa Kecamatan Palu Utara Tahun 2020.

\section{METODE PENELITIAN}

Penelitian ini adalah suatu penelitian deskriptif dengan pendekatan observasional. Lokasi penelitan, yaitu CV.Fajar Baru Kecamatan Palu Utara. Waktu penelitian dilaksanakan pada bulan Februari 2020. Populasi pada penelitian ini merupakan seluruh pekerja di bagian produksi CV.Fajar Baru Kecamatan Palu Utara sebanyak 60 karyawan. Variabel penelitian meliputi, posisi kerja adalah merupakan kondisi tubuh yang terbentuk secara alamiah oleh badan pekerja yang berhubungan dengan rutinitas kerja ataupun suatu pekerjaan. Yang dimaksud posisi kerja dalam penelitian ini adalah posisi kerja tubuh pekerja ketika sedang melakukan pekerjaan misal berdiri, mengangkat, memikul/memindahkan, pada proses penimbangan, pengorengan, penjemuran, pemotongan, polis, pemilahan kualitas rotan, dan mengebosan/pengeluaran untuk timbang box yang sesuai sesuai standard sedangkan kelelahan kerja adalah menurunnya produkifitas kerja serta menurunnya kemampuan atau ketahanan fisik tubuh manusia untuk keberlangsungan suatu aktifitas kegiatan yang harus dikerjakan yang diukur menggunakan rangsangan cahaya.

\section{Posisi Kerja}

\section{HASIL PENELITIAN}

Distribusi responden berdasarkan posisi kerja pada pekerja CV. Fajar Baru Kelurahan Kayumalue Ngapa Kecamatan Palu Utara ditampilkan dalam tabel 1. 
Tabel 1. Distribusi responden berdasarakan Posisi kerja pada pekerja CV. Fajar Baru Kelurahan Kayumalue Ngapa Kecamatan Palu Utara.

\begin{tabular}{lcc}
\hline \multicolumn{1}{c}{ Posisi kerja } & Frekuensi (orang) & $\%$ \\
\hline Sesuai & 0 & 0 \\
Tidak sesuai & 60 & 100 \\
\hline Total & 60 & 100 \\
\hline
\end{tabular}

Sumber: Data Primer, 2020

Data yang diperoleh menujukkan bahwa posisi kerja pada pekerja di CV. Fajar Baru Kelurahan Kayumalue Ngapa Kecamatan Palu Utara sebanyak 60 pekeja (100\%) kesemuanya menggambarkan tidak sesuai.

\section{Tingkat Kelelahan}

Tabel 2. Tingkat kelelahan kerja di CV. Fajar Baru Kecamatan Palu Utara.

\begin{tabular}{lcc}
\hline \multicolumn{1}{c}{ Tingkat kelelahan } & Jumlah (Orang) & $\%$ \\
\hline Normal & 5 & 8,3 \\
Ringan & 47 & 76,7 \\
Sedang & 8 & 15,0 \\
Berat & 0 & 0 \\
\hline Total & 60 & 100 \\
\hline
\end{tabular}

Pada tabel 2 menujukkan bahwa tingkat kelelahan tertinggi adalah kelelahan ringan 47 pekerja $(76,7 \%)$, sedang 8 pekerja $(15 \%)$ dan normal 5 pekerja $(8,3 \%)$.

\section{PEMBAHASAN}

\section{Posisi Kerja}

Berdasarkan hasil penelitian menujukan bahwa posisi kerja pada pekerja di CV. Fajar Baru Kelurahan Kayumalue Ngapa Kecamatan Palu Utara sebanyak 60 pekeja (100\%) tidak sesuai. Posisi kerja merupakan titik penentu dalam menganalisa keefektifan dari suatu pekerjaan. Bila posisi kerja yang dilakukan saat melakukan aktifitas sudah sesuai ergonomi maka hasil yang di peroleh akan baik namun sebaliknya bila posisi kerja tidak menggunakan analisa ergonomi maka akan di peroleh hasil yang tidak maksimal. ${ }^{6}$ Berdasarkan hasil pengamatan secara langsung pada pekerja rotan di CV. Fajar Baru didapatkan posisi kerja tidak sesuai disebabkan pada saat bekerja dengan posisi berdiri selama lebih dari 2 jam dan tidak menmanfaatkan waktu untuk istrahat, karena dari pihak perusahaan suda menentukan jam istrahat jam 12 kemudian masuk kembali jam 1, serta pekerja sering membungkuk dan mengangkat rotan, tulang belakang tidak lurus, memindahkan rotan dengan beban berat yang diangkat melebihi batas normal, dan posisi leher saat memikul beban terlalu miring. Serta posisi kerja yang dilakukan pekerja rotan tersebut akan berdapak pada kelelahan dan mengakibatkan kecelakaan kerja.

Salah satu penyebab posisi kerja tidak sesuai adalah keluhan muskuloskeleta. Muskuloskeleta adalah keluhan pada bagian otot skeletal yang dialami oleh seseorang mulai dari keluhan sangat ringan hingga sangat berat. Apabila otot mendapat beban yang berulang secara menetap dalam waktu yang lama, akan menimbulkan berbagai keluhan dan berdampak pada kerusakan, sendi, ligamen dan tendon. Kondisi seperti ini biasanya diistilahkan dengan keluhan muskuloskeletal disorders atau luka pada sistem muskuloskeleta disebabkan kelelahan pada saat bekerja yang tidak ergonomis .sebagai contoh keluhan sementara (reversible). Keluhan sementara adalah keluhan otot yang terjadi ketika otot menerima beban secara berulang dan menetap akan tetapi keluhan tersebut akan lenyap apabila pembebanan dihentikan.Keluhan permanen ialah keluhan otot yang bersifat menetap meskipun pembebanan kerja sudah dihentikan, tetapi rasa sakit pada otot masih terus dirasakan. Penelitian menunjukkan bahwa bagian otot yang kerap merasakan sakit 
adalah otot rangka (skeletal) yang meliputi bagian bawah,otot leher, tangan, jari, bahu, lengan, punggung, pinggang. Keluhan otot skeletal biasanya terjadi terjadi akibat kontraksi otot yang berlebih disebabkan beban yang sangat berat dengan waktu yang lama. ${ }^{7}$ Posisi kerja yang tidak menekan segi berakibat ketidaknyamanan serta berdampak kecelakaan ditempat kerja. $^{8}$

\section{Tingkat Kelelahan Kerja}

Masalah kelelahan adalah merupakan yang harus mendapat perhatian. Semua jenis pekerjaan baik formal dan informal menimbulkan kelelahan kerja. ${ }^{9}$ Kelelahan kerja berakibat pada pengurangan kapasitas kerja dan ketahanan tubuh. ${ }^{10}$ Berdasarkan penelitian bahwa sebagian besar pekerja mengalami kelalahan normal hanya 5 pekerja (8,3\%), ringan sebanyak 47 pekerja $(76,7 \%)$, dan kelelahan sedang 8 pekerja $(15,0 \%)$. Kelelahan kerja akan berdampak pada penurunan konsentrasi saat bekerja, penurunan aktifitas kerja dan meningkatkan kecelakaan kerja. Menurunnya aktifitas sama artinya dengan menurunnya produktivitas kerja. Apabila tingkat produktivitas seseorang menurun yang di akibatkan oleh faktor kelelahan tubuh maupun psikis maka dampaknya akan berpengaruh terhadap produktivitas perusahaan. ${ }^{7}$

Hasil pengukuran lansung dengan mengunakan reaction timer pada pekerja pengolahan rotan didapatkan tingkat kelelahan normal, ringan, dan sedang yang didapatkan pada pekerja CV. Fajar Baru pada pekerja pengolahan rotan yang mana kelelahan kelelahan normal yaitu pekerja bekerja menggunakan mesin sehingga mempermudah pekerjaan pekerja dan waktu bekerja dimanfaatkan dengan baik. Kelelahan sedang diakibatkan oleh kondisi lingkungan kerja yang bersuhu tinggi sehingga mengakibatkan pekerja sering mengeluarkan keringat, lama berdiri selama 4 jam tanpa selingan waktu istirahat, mengangkat beban berat yang melebihi kemampuan, serta penyebab Kelelahan yang dialami pekerja di CV. Fajar Baru mendapatkan keadaan yang tidak sama dari setiap orang, namun kesemuanya berdampak pada kehilangan prodiktifitas kerja serta kemampuan ketahanan tubuh. Dewasa ini, produktivitas individu mendapat perhatian cukup besar. Hal ini didasarkan pada pemikiran bahwa sebenarnya produktivitas manapun bersumber dari individu yang melakukan kegiatan. Namun individu yang dimaksud adalah individu sebagai tenaga kerja yang memiliki kualitas kerja yang memadai. ${ }^{11}$

Faktor yang paling besar sebagai penyebab turunnya atau rendahnya aktifitas di akibatkan oleh kelelahan kerja yang disebabkan oleh ketidak nyamanan posisi kerja saat bekerja (ergonomi). Selain itu juga di dukung oleh faktor lingkungan kerja yang kurang nyaman sehingga memicu timbulnya kelelahan pada tenaga kerja. Faktor ergonomi tersebut dapat berupa hubungan kerja, tanggung jawab, suasana kerja, , konstruksi mesin, sikap dan cara kerja yang salah di tempat kerja. ${ }^{3}$ Jika tingkat produktivitas seorang tenaga kerja terganggu dikarenakan adanya faktor kelelahan fisik maupun psikis, maka ini akan berdampak juga pada perusahaan yang berupa penurunan produktivitas perusahaan. ${ }^{9}$

Bersumber pada riset yang dicoba oleh Widjasena dengan riset Keletihan Kerja pada Kegiatan Pengamplasan Bagian Finishing PT. Ebako Nusantara Semarang, kalau pekerja lama bekerja dengan bentuk badan janggal, terus menjadi banyak tenaga yang diperlukan buat mempertahankan keadaan tersebut sehingga akibat keletihan yang ditimbulkan terus menjadi kokoh. Kegiatan pengamplasan bertabiat statis sebab posisi kerja cenderung diam pada titik porosnya dengan cuma terdapat gerakan tangan, kaki, serta kepala. Pada perilaku kerja statis, peredaran darah ke otot menurun sehingga glukosa serta oksigen ke otot jadi terhambat serta wajib memakai cadangan yang terdapat serta sisa metabolisme tidak dapat dibuang. Oleh sebab itu, otot yang bekerja secara statis hendak terasa perih serta langsung jadi letih. ${ }^{12}$ Kelelahan dan kelemahan yang seringkali diakibatkan oleh aliran darah ke jantung menurun, sehingga otot jantung mengalami ktegangan estra yang akan membuat kita kelelahan. $^{13}$

Berdasarkan penelitian yang dilakukan oleh Widjasena dengan penelitian Kelelahan Kerja pada Bagian Pemolesan Bagian Finishing PT. Ebako Nusantara Semarang bahwa kelelahan akan semakin meningkat ketika seseorang bekerja dengan postur janggal dan menggunakan energi yang banyak untuk saat mempertahankan kondisi tersebut. Aktivitas 
pemolesan bersifat menetap karena posisi kerja cenderung diam pada titik porosnya dengan hanya ada gerakan tangan, kaki, dan kepala. ${ }^{14}$ Pada sikap kerja demikian, peredaran darah ke otot menurun sehingga glukosa dan oksigen ke otot menjadi berkurang dan harus menggunakan cadangan yang ada dan sisa metabolisme tidak bisa dibuang. Oleh karena itu, otot yang bekerja secara menetap akan terasa sakit dan langsung menjadi lelah. ${ }^{12}$ Solusi yang dapat dilakuan dengan menciptakan tempat kerja yang aman, sehat dan bebas dari pencemaran lingkungan. Dengan demikian dapat melindungi setia pekeja dan bebas dari kecelakaan. ${ }^{15}$

\section{SIMPULAN DAN SARAN}

Kesimpulan dari penelitian di Kecamatan Palu Utara Bahwa posisi kerja pada pekerja pengolahan rotan di CV. Fajar Baru Kecamatan Palu Utara didapatkan semuanya tidak sesuai. Kelelahan pada pekerja pengolahan rotan di CV. Fajar Baru Kelurahan Kayumalue Ngapa Kecamatan Palu Utara menunjukan normal sebanyak lima pekerja (delapan koma tiga persen), ringan empat puluh tujuh pekerja (Tujuh puluh enam koma tujuh persen) dan kelelahan sedang delapan orang pekerja (Lima belas persen). Disarankan pihak perusahaan memperhatikan posisi kerja pekerja yang benar seperti lama berdiri 2 jam harus diselingi waktu istirahat, posisi mengangkat tulang belakang lurus, tidak terlalu membungkuk dan posisi saat memindahkan beban harus dekat dengan tubuh, sebaiknya gerakan harus statis sehingga tidak menimbulkan kelelahan saat bekerja, agar pihak perusahaan dapat memperbaikinya dan pekerja dapat bekerja.

\section{DAFTAR PUSTAKA}

1. Widjasena B, Ekawati E. Hubungan Beban Kerja Fisik Manual Dan Iklim Kerja Terhadap Kelelahan Pekerja Konstruksi Bagian Project Renovasi Workshop Mekanik. J Kesehat Masy. 2016;4(3):425-35.

2. Amalia NR, Wahyuni I, Ekawati. Hubungan Postur Kerja Dengan Keluhan Kelelahan Kerja Pada Operator Container Crane Pt. Terminal Peti Kemas Semarang. J Kesehat Masy. 2017;5(5):290-8.

3. Hastuti DD. Hubungan Antara Lama Kerja Dengan Kelelahan Pada Pekerja Konstruksi di PT. Nusa Raya Cipta Semarang. Universitas Negeri Semarang; 2015.

4. Jannah N. Hubungan Antara Beban Kerja Dengan Kelelahan Kerja Pada Karyawan Bagian Cutting PT. Dan Liris Banaran Kabupaten Sukoharjo. 2014;

5. Aryantiningsih DS, Husmaryuli D. Kejadian Kecelakaan Kerja Pekerja Aspal Mixing Plant (AMP) dan Batching Plant di PT. LWP Pekanbaru Tahun 2015. J Kesehat Masy Andalas. 2016;10(2):145-50.

6. Ramdani A. Hubungan Antara Posisi Kerja dan Masa Kerja Terhadap Kejadian Low Back Pain Pada Penambang Belerang di Gunung ljen. Universitas Muhammadiyah Malang; 2018.

7. Wardaningsih I. Pengaruh Sikap Kerja Duduk Pada Kursi Kerja Yang Tidak Ergonomik Terhadap Keluhan Otot-otot Skeletal Bagi Pekerja Wanita Bagian Mesin Cucuk di PT Iskandar Indah Printing Textile Surakarta. Universitas Sebelas Maret Surakarta; 2010.

8. Natosba J, Jaji. Pengaruh Posisi Ergonomis terhadap Kejadian Low Back Pain Pada Penenun Songket di Kampung BNI 46. J Keperawatan Sriwij. 2016;3(2):8-16.

9. Muizzudin A. Hubungan Kelelahan Dengan Produktivitas Kerja Pada Pekerja Tenun di PT. Alkatex Tegal. Unnes J Public Heal. 2013;2(4):1-8.

10. Harahap LK. Pengaruh Stress Kerja Dan Lama Kerja Terhadap Tingkat Kelelahan Karyawan Di Pt Zaitun Indo Citra Perkasa Medan. Universitas Medan Area; 2018.

11. Roshadi I. Hubungan Kelelahan Kerja Dengan Produktivitas Kerja Karyawan di Fakultas Dakwah dan Komunikasi UIN Sunan Kalijaga Yogyakarta. Universitas Islam Negeri Sunan Kalijaga; 2014.

12. Ismiarni H, Widjasena B, Jayanti S. Hubungan Postur Kerja Dengan Kejadian Kelelahan Otot Punggung Pada Pekerja Mebel Bagian Pengamplasan Di Pt. X Jepara. J Kesehat Masy. 2017;5(1):369-77. 
13. Saleh LM, Russeng SS, Rahim MR, Awaluddin, Tadjuddin I. Teknik Relaksasi Otot Progresif Pada Air Traffic Controller (ATC). Yogyakarta: Deepublish; 2019.

14. Tidy T, Widjasena B, Jayanti S. Hubungan Postur Kerja Dengan Kelelahan Kerja Pada Aktivitas Pengamplasan Bagian Finishing Pt Ebako Nusantara Semarang. J Kesehat Masy. 2017;5(5):397-405.

15. Kurniasih E, Pardi, Raudah. Teaching Factory. Yogyakarta: Andi; 2020. 